\title{
THERMAL PROPERTIES OF CARBOXYMETHYL CELLULOSE ACETATE BUTYRATE
}

\author{
MOHAMED EL-SAKHAWY, HEBAT-ALLAH S. TOHAMY*, AHMED SALAMA and \\ SAMIR KAMEL \\ Cellulose and Paper Department, National Research Centre, \\ 33, El Bohouth Str., P.O. 12622, Dokki Giza, Egypt \\ \Corresponding author: H.-A. S. Tohamy, hebasarhan89@yahoo.com
}

Received February 19, 2019

\begin{abstract}
From $\alpha$-cellulose extracted from sugar cane bagasse, carboxymethyl cellulose (CMC), carboxymethyl cellulose acetate (CMCA) and carboxymethyl cellulose acetate butyrate (CMCAB) have been prepared, characterized and evaluated by TGA and DSC. TGA decomposition curves of CMCAB showed three decomposition stages, while cellulose, CMC and CMCA revealed two decomposition stages. The TGA of cellulose and CMC showed residual weight of 19.6 and $34.2 \%$, respectively, at $600{ }^{\circ} \mathrm{C}$, which indicates the presence of a fraction of non-volatile components. Meanwhile, the residual weight of $\mathrm{CMCA}$ and $\mathrm{CMCAB}$ was very low, which indicates their high purity. The activation energy and thermal stability of CMCAB were higher than those of the other derivatives due to the decomposition of the amorphous part during the modification. The DSC curves showed that CMCAB is a glassy thermoplastic material with glass transition temperature of $138.35^{\circ} \mathrm{C}$, whereas endothermic melting was found at $200^{\circ} \mathrm{C}$.
\end{abstract}

Keywords: bagasse, amphiphilic cellulose, carboxymethyl cellulose acetate butyrate, thermal properties, TGA, kinetics

\section{INTRODUCTION}

Chemical modification of renewable polysaccharides is an important technique to modify their properties to make them suitable for specific applications. ${ }^{1}$ Carboxymethyl cellulose (CMC) is the most important cellulose derivative. It is a non-toxic water soluble heteropolysaccharide derived from cellulose with high molecular weight. It has been used in chemical and pharmaceutical industries as cobinder, rheology modifier, anti-redeposition aid, water thickener and to enhance product quality and stability. ${ }^{2}$

CMC of low DS (0.2-0.7) has free hydroxyl groups, which can be further esterified by organic acid anhydrides to attain either single or mixed ester derivatives. The sodium salts of such carboxyalkyl acetyl celluloses are dissolved uniformly in water and in aqueous organic solvents. ${ }^{3}$

Amphiphilic polymers contain hydrophobic and hydrophilic units, which, in turn, tend to selforganize (self-assembly) in aqueous environment. Hydrophilic and hydrophobic moieties allocation in the molecule affects its properties. ${ }^{4}$
Carboxymethyl cellulose acetate butyrate (CMCAB), as an amphiphilic cellulose ester that has hydroxyl, ester and acid functional groups, could be synthesized by esterification of CMC sodium salt. CMC is activated and protonated by sulfuric acid, which converts it to the free acid form, $\mathrm{CMC}-\mathrm{H}$; the swollen $\mathrm{CMC}-\mathrm{H}$ is subsequently esterified with acetic and butyric acid anhydrides in one step. Since mixed esterification is occurring simultaneously, the DS of each ester will depend on the amount of the two acid anhydrides used. ${ }^{5} \mathrm{CMCAB}$ can be used as sizing agent, protective coating, carrier and stabilizer for metallic pigments. Also, it can be used as drug particle carrier in oral drug delivery systems and $\mathrm{pH}$-controlled release of drugs and finally used as rheological modifier in many paint formulations. ${ }^{6}$

$\mathrm{CMCAB}$ is soluble in many organic solvents and it can be stabilized in aqueous media with partial neutralization of its acid form. The hydrophobicity of CMCAB is due to higher DS of acetyl and butyryl groups. ${ }^{6}$ It has different structural characteristics, which can affect its 
thermal decomposition. $\mathrm{CMCAB}$ is a glassy, high molecular weight polymer with a high glass transition temperature (Tg). ${ }^{5}$ The $\mathrm{Tg}$ of a material characterizes the range of temperatures over which amorphous materials are converted from a hard and fairly brittle "glassy" state to a viscous or rubbery state. ${ }^{7}$

The chemistry of cellulose and wood pyrolysis has been previously reviewed. ${ }^{8}$ Thermogravimetric analysis (TGA) is a method that records sample weight loss against temperature under controlled heating rate and inert atmosphere. Differential thermogravimetric analysis (DTA) curves result from TGA curves, and are applied to evaluate the pyrolysis kinetics of biomass. ${ }^{8}$ Biomass pyrolysis could be defined as the direct thermal decomposition of organic matter in the absence of oxygen to obtain solid, liquid and gaseous products. ${ }^{9}$ Meanwhile, differential scanning calorimetry (DSC) is aimed at providing information about the glass transition temperature and the crystalline phase. ${ }^{10}$

In this work, the thermal properties of cellulose and its derivatives were characterized by TGA and DSC to identify polymer degradation and glass transition temperatures.

\section{EXPERIMENTAL \\ Materials}

Chemical pulp was prepared from domestic sugarcane bagasse, as described elsewhere. ${ }^{11}$ The chemical analysis of the resulting pulp was the following: $\alpha$-cellulose $94.2 \%$, lignin $0.3 \%$, hemicellulose $3.4 \%$ and ash $0.4 \%$ ). Carboxymethyl cellulose (CMC), carboxymethyl cellulose acetate (CMCA) and carboxymethyl cellulose acetate butyrate (CMCAB) were prepared from bagasse pulp by the methods explained previously in detail. ${ }^{5} \mathrm{CMC}$ has a 0.45 degree of substitution (DS) by carboxymethyl (CM) group; CMCA has a $0.26 \mathrm{CM}$ DS and $2.27 \%$ acetate and $\mathrm{CMCAB}$ has a $0.24 \mathrm{CM}$ DS, $4.75 \%$ acetate and $24.04 \%$ butyrate.

\section{Thermogravimetric analysis (TGA)}

TGA studies were carried out on the prepared polymer powders by using a Perkin Elmer thermogravimetric analyzer with nitrogen as purge gas. The specimen, approximately of $4.876 \mathrm{mg}$, was weighed in a platinum pot and heated to $600{ }^{\circ} \mathrm{C}$ at 10 ${ }^{\circ} \mathrm{C} / \mathrm{min}$ in nitrogen atmosphere.

\section{Differential scanning calorimetry (DSC)}

Thermal scans were performed using TA Instruments SDT Q600 V20.9 equipment. Dry $\mathrm{N}_{2}$ was used as purge gas. Specimens were heated at rates of
$10{ }^{\circ} \mathrm{C} / \mathrm{min}$, in the temperature range from room temperature to $600{ }^{\circ} \mathrm{C}$.

\section{RESULTS AND DISCUSSION}

Thermogravimetric analysis (TGA) and differential thermogravimetric analysis (DTA)

The thermal parameters for each reaction stage were determined from thermal analysis curves as the initial $\left(\mathrm{T}_{\mathrm{i}}\right)$ and final $\left(\mathrm{T}_{\mathrm{f}}\right)$ temperatures of decomposition, and $(\Delta \mathrm{m})$ temperature peak at maximum rate of weight loss.

The TGA curves for cellulose, CMC, CMCA and $\mathrm{CMCAB}$ are given in Figure 1. In general, the CMCAB decomposition curve revealed three decomposition steps, while cellulose, CMC and CMCA revealed two decomposition steps. The difference in the chemical composition of cellulose, CMC, CMCA and CMCAB causes the observed differences in thermal decomposition behavior and thermal stability. ${ }^{12}$

\section{Thermogravimetric curves of cellulose, CMC and CMCA}

The TGA/DTA data of cellulose, CMC and CMCA are summarized in Table 1. The TGA of cellulose and CMC showed a weight loss of 80.4 and $65.8 \%$, respectively, at $600{ }^{\circ} \mathrm{C}$, which indicated that the neat cellulose and CMC contain a fraction of non-volatile components. As shown in Table 1, the residual weight of CMCA and $\mathrm{CMCAB}$ was very low; this indicates their high purity and absence of inorganic residues.

As shown in Figure 1, the thermal decomposition processes of cellulose, CMC and CMCA could be divided into two major reaction steps, where the first weight loss of cellulose, CMC and CMCA was of 4.861, 6.489 and $7.932 \%$ at $60.7,49.2$ and $51.3{ }^{\circ} \mathrm{C}$, respectively. The first weight loss is mainly attributed to the evaporation of physically bound water in the cellulosic structure. The weight losses in the first step were high for CMC and CMCA, which may be attributed to their porous configuration, compared with cellulose.

This first weight loss was followed by the main decomposition stage at 353,295 and $330{ }^{\circ} \mathrm{C}$ (with a weight loss of 75.54, 59.30 and $91.98 \%$ ) for cellulose, CMC and CMCA, respectively. The main weight losses were assigned to fragmentation associated with the pyrolytic decomposition, leading to the formation of aromatized units and the decomposition of the carbonaceous residues. ${ }^{13,14}$ The second reaction involved pyrolytic decomposition by breaking of 
glucosidic bonds and the linear molecules were converted to lower molecular weight molecules. The weight loss of the CMC sample was due to the decarboxylation of carboxylic groups in $\mathrm{CMC}$ and the loss of $\mathrm{CO}_{2}$. The conversion of cellulose to CMC affects both the molecular structure and bonding energy, which causes the different thermal behavior of CMC. ${ }^{15}$ Once the degraded molecules were produced, they were exposed to additional decomposition, as they were thermally unstable, and this reaction proceeded until the ends of the polymer chains, leading to aromatized units and finally to a cross-linked carbon skeleton.
This latter depolymerization type was considered as the propagation step. ${ }^{16}$

The mechanism can be represented as: $:^{17}$

$$
\begin{array}{lll}
\text { Initiation: } & \mathrm{A} & \longrightarrow \mathrm{B} 1 \\
\text { Propagation: } & \mathrm{B}_{1} & \longrightarrow \mathrm{B}_{2}+\mathrm{L}, \\
& \mathrm{B}_{2} & \longrightarrow \mathrm{B}_{3}+\mathrm{L}, \\
& \mathrm{B}_{\mathrm{n}} & \longrightarrow \mathrm{B}_{\mathrm{n}+1}+\mathrm{L}, \\
& \sum B_{\mathrm{n}} & \longrightarrow \sum B_{\mathrm{n}+1}+\mathrm{nL}
\end{array}
$$

where A denotes initial molecules of cellulose, $\mathrm{CMC}$, or CMCA; $\mathrm{B}_{1}, \mathrm{~B}_{2}, \ldots \mathrm{B}_{\mathrm{n}}$, are fragmented molecules; and $\mathrm{L}$ denotes volatile products.

Table 1

TGA data of cellulose, CMC, CMCA and CMCAB

\begin{tabular}{lccccc}
\hline \multirow{2}{*}{ Sample } & $\begin{array}{c}\text { Weight loss } \\
\text { at } 600{ }^{\circ} \mathrm{C}, \%\end{array}$ & $\begin{array}{c}\text { Residual weight, } \\
\%\end{array}$ & \multicolumn{3}{c}{ Temp. of steps in TGA, ${ }^{\circ} \mathrm{C}$} \\
\cline { 4 - 6 } & 80.4 & 19.6 & Step 1 & Step 2 & Step 3 \\
\hline Cellulose & 65.8 & 34.2 & 60.7 & 353 & - \\
CMC & 99.9 & 0.1 & 49.2 & 295 & - \\
CMCA & 95.2 & 4.8 & 51.3 & 330 & - \\
CMCAB & & 46.2 & 278 & 358 \\
\hline
\end{tabular}
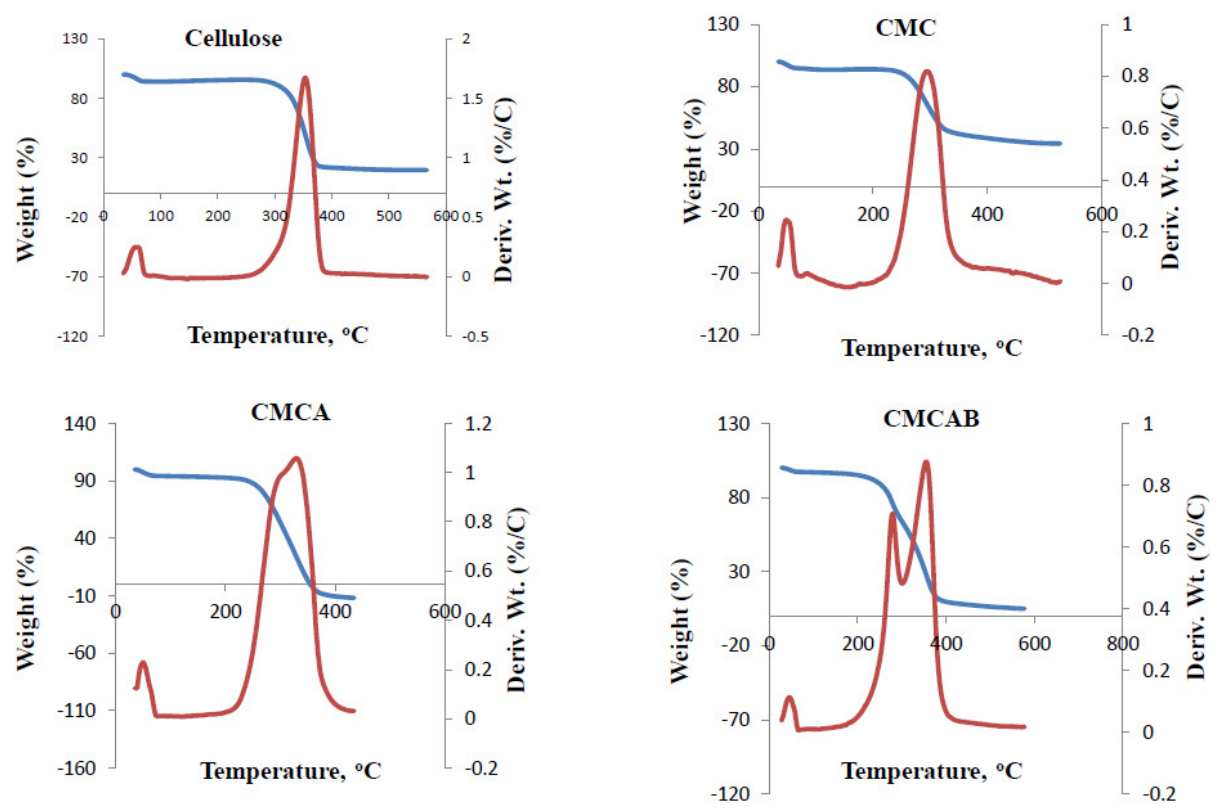

Figure 1: TGA and DTA curves of cellulose, CMC, CMCA and CMCAB

However, the main weight loss of CMC (295 $\left.{ }^{\circ} \mathrm{C}\right)$ was shifted to lower temperature than that of cellulose $\left(353{ }^{\circ} \mathrm{C}\right)$, which may confirm the lower thermal stability of CMC. ${ }^{18}$ This is due to interand intra-molecular hydrogen bonds between cellulose fibers in contrast to CMC. Mercerization with $\mathrm{NaOH}$ during $\mathrm{CMC}$ preparation increased the amorphous structure of $\mathrm{CMC}$. Also, the main weight loss of CMCA $\left(330{ }^{\circ} \mathrm{C}\right)$ was shifted to lower temperature than that of cellulose, but was still higher than that of CMC, which may confirm the lower thermal stability of CMCA than that of 
cellulose, but at the same time, its thermal stability is higher than that of CMC. This finding concurs with another study on bagasse, which concluded that the onset degradation temperature of bagasse decreased as a result of chemical modifications. ${ }^{19}$

\section{Thermogravimetric curves of CMCAB}

The thermal decomposition process of CMCAB could be recognized by the three main reaction steps. The initial weight loss between 30.8-61.7 ${ }^{\circ} \mathrm{C}$, with a maximum at $46.2{ }^{\circ} \mathrm{C}$ (average weight loss of $2.76 \%$ ), was likely caused by the loss of moisture content. The second weight loss at $278{ }^{\circ} \mathrm{C}$ (mass loss of $33 \%$ ) was the result of several coincident processes, such as dehydration, depolymerization, and decomposition. In other words, the weight loss in the second stage was due to dehydroxylation, combined with pyrolytic fragmentation, leading to the development of aromatized units and volatile products. $^{20}$ There was a small weight loss in the second step, comparing to the third step, showing slow decomposition of $\mathrm{CH}_{2}$-linkages, $\mathrm{H}$-bonding and slow interactions between the polymers. ${ }^{21}$

The third decomposition step between 310-600 ${ }^{\circ} \mathrm{C}$ represented the maximum degradation rate event at $357{ }^{\circ} \mathrm{C}$ (average weight loss of $59.4 \%$ ), which was ascribed to the decomposition of the carbonaceous residues to form low molecular weight gaseous products, i.e., the thermal decomposition was likely related to the combustion of the crosslinked aromatized units formed in the $2^{\text {nd }}$ step. ${ }^{20}$ Compared with cellulose, $\mathrm{CMC}$ and CMCA, CMCAB shows a higher thermal stability due to the synergetic effect of both ether and ester groups towards thermal stabilization.

These three steps may match the three steps suggested by Chatterjee as representing the thermal degradation of cellulosic materials: ${ }^{22}$

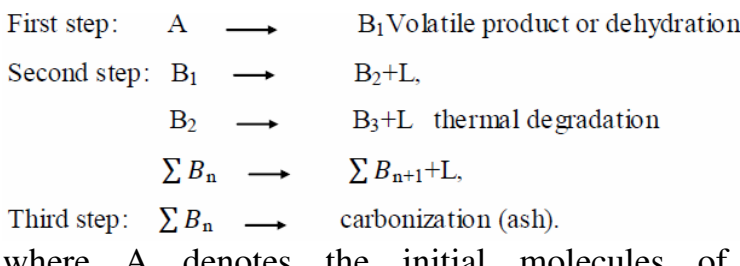
where $A$ denotes the initial molecules of CMCAB; $B_{1}, B_{2}, \ldots B_{n}$ are fragmented molecules and $L$ represents volatile products.

The DTA curves of cellulose, CMC and CMCA (Fig. 1) show two separate endothermic processes. The maxima of the first endotherms appear at $60.7,49.2$ and $51.3{ }^{\circ} \mathrm{C}$ for cellulose,
CMC and CMCA, respectively, which can be attributed to water evaporation. Meanwhile, the second endotherm with peak maxima appearing at 353, 295 and $330{ }^{\circ} \mathrm{C}$ for cellulose, CMC and CMCA, respectively, can be attributed to pyrolytic fragmentation. ${ }^{13,14}$ The DTA of CMCAB (Fig. 1) shows three endothermic processes, one separate process at $46.2{ }^{\circ} \mathrm{C}$, attributed to water evaporation and two overlapping endothermic processes at 278 and $357{ }^{\circ} \mathrm{C}$, which are ascribed to the decomposition of cellulose.

The endothermic temperatures for $\mathrm{CMC}$ and CMCA shifted towards lower values than that of cellulose. This shift showed that the functionalized sample was less thermally stable in contrast to cellulose because of the increase in the amorphous region in the $\mathrm{CMC}$ and $\mathrm{CMCA}$ chains, which decomposed more rapidly than the crystalline part. Meanwhile, an endothermic reaction at $357{ }^{\circ} \mathrm{C}$ for $\mathrm{CMCAB}$ was shifted to higher values than for cellulose. This indicated that the CMCAB is thermally more stable than cellulose. This is due to the decomposition of the amorphous parts of CMC during the modification. This could be confirmed by the crystallinity index measured from the infrared spectra, thus, the crystallinity index of CMCAB (2.44) is higher than that of cellulose (1.96), CMCA (1.62) and CMC (0.82). ${ }^{23}$

\section{Mechanism of thermal degradation of CMCA and CMCAB}

The thermal degradation of CMCA and $\mathrm{CMCAB}$ was started with the production of acetic and/or butyric acid, followed by dehydration, as the formed acids catalyzed the dehydration reaction. At 330 and $357{ }^{\circ} \mathrm{C}$, for $\mathrm{CMCA}$ and $\mathrm{CMCAB}$, respectively, the complete removal of ester groups occurs, as well as the formation of a $\mathrm{C}=\mathrm{C}$ conjugated system, mostly due to the formation of carbonaceous residue. ${ }^{24}$

\section{Kinetics of thermal decomposition of cellulose, CMC, CMCA and CMCAB}

Generally, the thermal decomposition of polymeric materials can be symbolized by the following equation: ${ }^{22}$

$\mathbf{A}_{\text {(Solid) }}$

Thermogravimetric analysis data can be investigated to calculate the activation energy of the thermal degradation process. The general 
correlation equations used in the Coats-Redfern method are:

$\begin{array}{ll}\log \left[\frac{1-(1-\alpha)^{1-n}}{\mathrm{~T}^{2}(1-\mathrm{n})}\right]=\log \frac{A R}{\beta E}\left[1-\frac{2 R T}{E}\right]-\frac{E}{2 \cdot 303 R T} & \text { for } \mathrm{n} \neq 1 \\ \log \left[\frac{-\log (1-\alpha)}{\mathrm{T}^{2}}\right]=\log \frac{A R}{\beta E}\left[1-\frac{2 R T}{E}\right]-\frac{E}{2.303 R T} & \text { for } \mathrm{n}=1\end{array}$

where $\alpha$ is the fractional conversion, $n$ is the order of degradation reaction, $R$ is the gas constant (in $\mathrm{kJ} / \mathrm{mol} . \mathrm{K}$ ), $T$ is the temperature (in $\mathrm{K}$ ), $A$ is the frequency factor $\left(\mathrm{s}^{-1}\right), \quad B$ is the heating rate $(\mathrm{K} / \mathrm{min})$ and $E$ is the activation energy.

From the above equation, plotting $\{\log 10[1-(1$ $\left.\left.-\alpha)^{1-n}\right] / T^{2}(1-n)\right\}$ against $1 / T$ using different $n$ values should offer a straight line, with the most proper value of $n$. Thus, the method of least squares was applied for the equation, taking various $n$ values (from 0 to 3.0) and calculating for each value of $n$, the correlation coefficient $(r)$ and standard error estimation (SE). The activation energies were estimated from the slope $(\mathrm{E} / 2.303 \mathrm{R})$, while frequency factors were estimated from the intercept $(\log A R / B E)$ of the Coats-Redfern equation with the most proper value of $n, 25$ as shown in Figure 2. The calculated energies of the activation values in the first zone (Table 2) increased with increasing the substitute groups to cellulose. The calculated energy of activation for $\mathrm{CMCAB}$ was higher compared to those of CMCA, CMC and cellulose. In the second zone, the activation energy values (Table 2) decreased with the formation of CMC due to the solubilization of some cellulosic fibers by sodium hydroxide during the carboxymethylation step. This indicates that the thermal stability of cellulosic chains decreased with increasing the degree of substitution of carboxymethyl groups.

Meanwhile, the activation energy of CMCA slightly increased, compared to that of CMC, but still remained lower than that of cellulose due to partial decomposition of the amorphous parts in CMC esters. In addition, the activation energy of CMCAB was the highest due to the decomposition of the amorphous parts of CMC during the modifications. ${ }^{26}$

\section{Differential scanning calorimetry (DSC)}

The occurrence of the chemical reaction could be proved by thermal analysis. The DSC curves of cellulose, CMC, CMCA and CMCAB are shown in Figure 3.

The DSC curve of cellulose shows two endothermic peaks at $72.1{ }^{\circ} \mathrm{C}$ (from 60.9 to 83.3 ${ }^{\circ} \mathrm{C}$ ), which are ascribed to moisture evaporation, and an endothermic peak at $358{ }^{\circ} \mathrm{C}$ (from 330 to $387{ }^{\circ} \mathrm{C}$ ), which is attributed to the dehydration/decomposition of cellulose. This behavior is associated to the complete decomposition of cellulose, leading to a minute solid residue. ${ }^{27} \mathrm{CMC}$ shows a broad endothermic band, attributed to the lower thermal stability of CMC.

Table 2

Thermoanalytical and thermodynamic data of the thermal decomposition steps of cellulose, CMC, CMCA and CMCAB samples

\begin{tabular}{lcccccc}
\hline Sample & Stage & $\begin{array}{c}\text { TGA range, } \\
{ }^{\circ} \mathrm{C}\end{array}$ & $\begin{array}{c}\text { DTA peak, } \\
{ }^{\circ} \mathrm{C}\end{array}$ & $\begin{array}{c}\text { Mass } \\
\text { loss, } \%\end{array}$ & $n$ & $\begin{array}{c}\mathrm{E}, \\
\mathrm{kJ} \mathrm{mol}^{-1}\end{array}$ \\
\hline \multirow{3}{*}{ Cellulose } & $1^{\text {st }}$ & $37.1-84.3$ & 60.67 & 4.86 & 1.5 & 45.8 \\
& $2^{\text {nd }}$ & $315-392$ & 353 & 75.5 & 2 & 95.30 \\
CMC & $3^{\text {rd }}$ & - & - & - & - & $\Sigma E=141.1$ \\
& $1^{\text {st }}$ & $36.9-61.4$ & 49.2 & 6.49 & 1.5 & 51.9 \\
CMCA & $2^{\text {nd }}$ & $245-345$ & 295 & 59.3 & 2 & 63.77 \\
& $3^{\text {rd }}$ & - & - & - & - & $\Sigma E=115.7$ \\
& $1^{\text {st }}$ & $39.8-62.9$ & 51.3 & 7.93 & 1.5 & 56.19 \\
CMCAB & $2^{\text {nd }}$ & $241-417$ & 329 & 92.0 & 2 & 68.01 \\
& $3^{\text {rd }}$ & - & - & - & - & $\Sigma E=124.2$ \\
& $1^{\text {st }}$ & $30.8-61.7$ & 46.2 & 2.76 & 1.5 & 62.66 \\
& $2^{\text {nd }}$ & $259-296$ & 278 & 33.0 & 2 & 75.02 \\
& $3^{\text {rd }}$ & $310-405$ & 358 & 59.4 & 2 & 41.3 \\
& & & & & & $\Sigma E=179$ \\
\hline
\end{tabular}




\section{MOHAMED EL-SAKHAWY et al.}
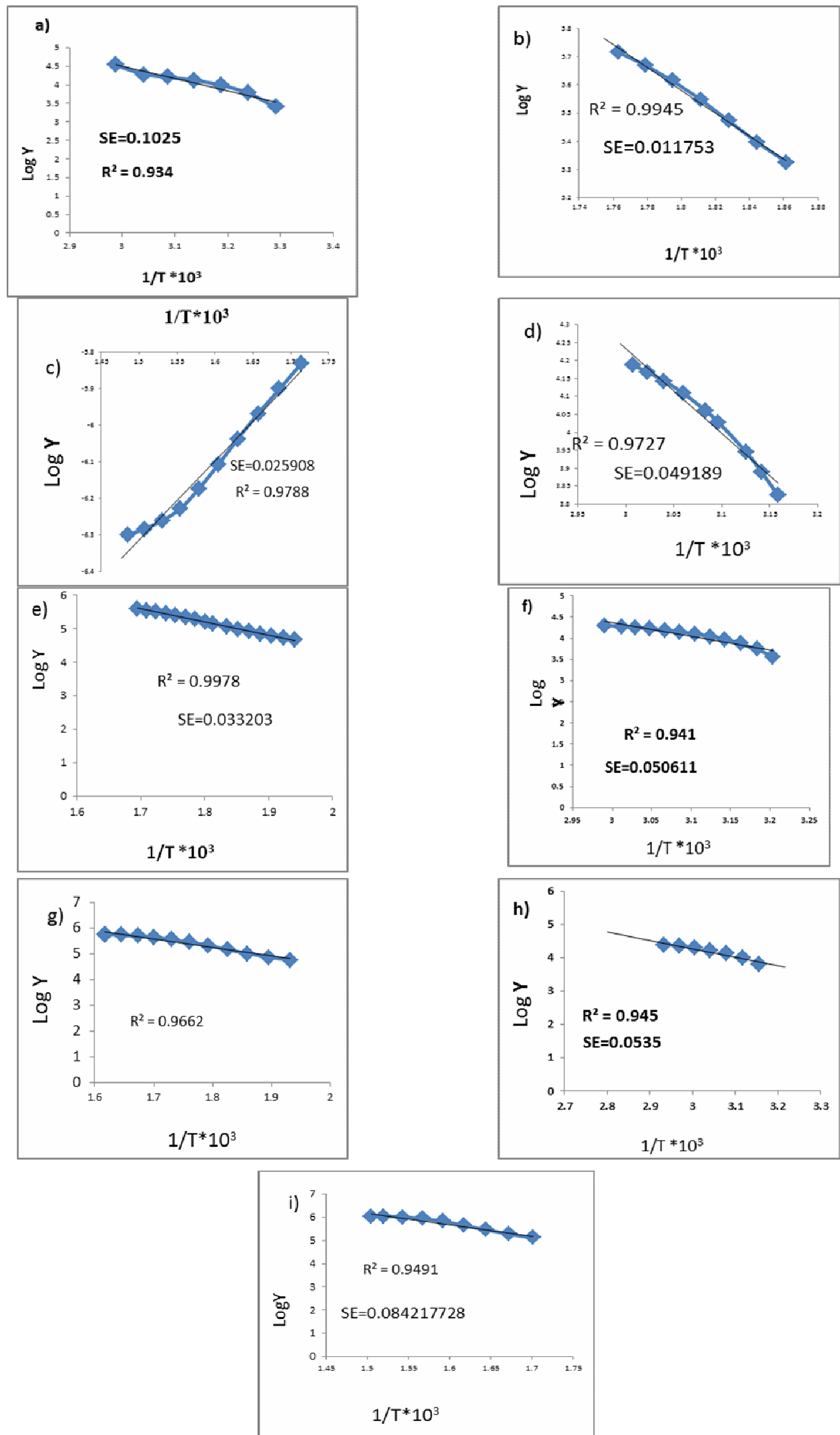

Figure 2: Thermograms of a) $1^{\text {st }}$, b) $2^{\text {nd }}$, c) $3^{\text {rd }}$ stages of CMCAB; d) $1^{\text {st }}$, e) $2^{\text {nd }}$ stages of CMCA; f) $1^{\text {st }}$, g) $2^{\text {nd }}$ stages of CMC and h) $1^{\text {st }}$, i) $2^{\text {nd }}$ stages of cellulose 

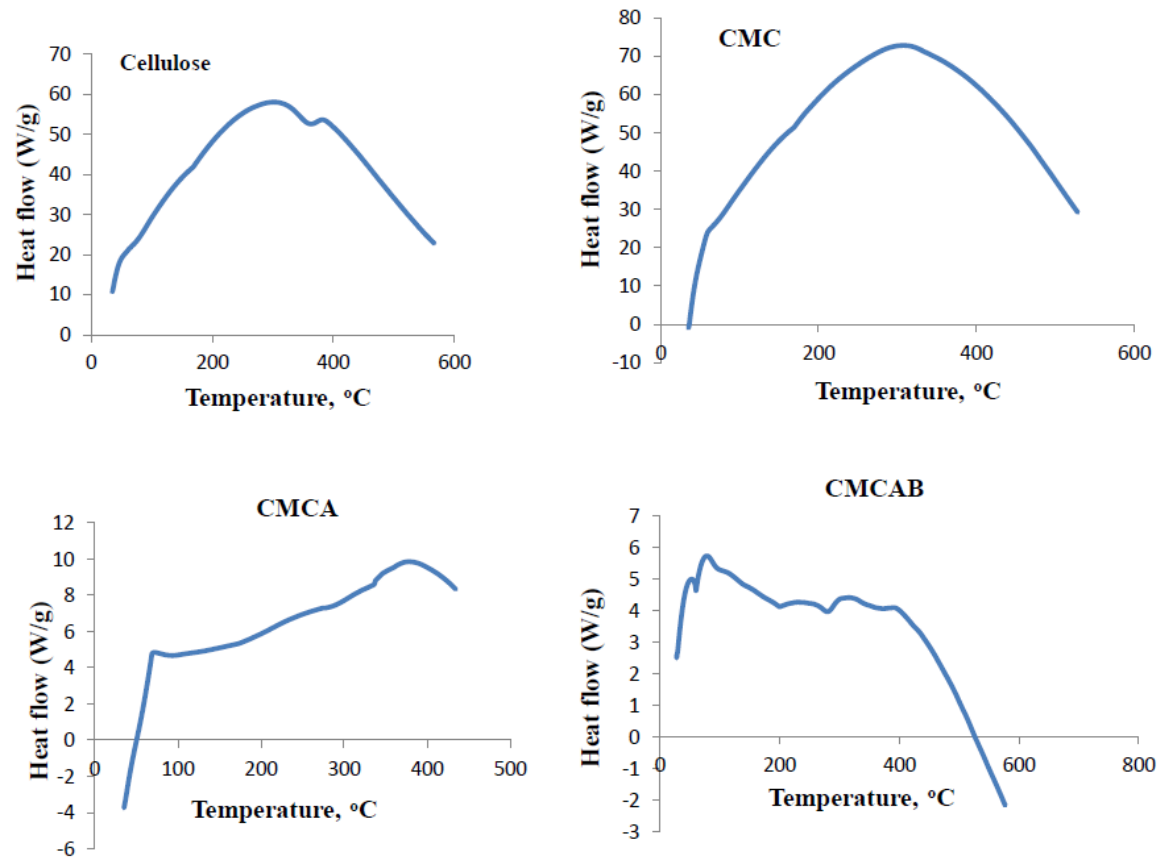

Figure 3: DSC curves of cellulose, CMC, CMCA and CMCAB, respectively

As seen in Figure 3, the DSC thermogram indicates that the $T_{m}$ of CMCA and CMCAB shifted to 281 and $200{ }^{\circ} \mathrm{C}$, respectively, compared to $358{ }^{\circ} \mathrm{C}$ for bulk cellulose. The lower $\mathrm{T}_{\mathrm{m}}$ of CMCA and CMCAB was caused by the nanosized particles of CMCA and $\mathrm{CMCAB}$, which show wider superficial area and degrade easier than bulk cellulose. ${ }^{28}$ Each chemical bond between atoms with a neighboring atom provides cohesive energy. The atom cohesive energy is directly associated with the required thermal energy to free the atom from the solid. Atoms near the surface have reduced cohesive energy and fewer bonds, so lower energy is required to be free from the solid phase. So, surface $T_{m}$ occurs at temperatures much lower than that for bulk melting. The decrease of $\mathrm{T}_{\mathrm{m}}$ for nanoparticle materials (high surface/volume ratio) was the result for this effect. ${ }^{29}$

In the case of CMCA and CMCAB, there are new bands at 326 and $359{ }^{\circ} \mathrm{C}$, when compared to cellulose and CMC, which are attributed to the decomposition of the synthesized copolymer and confirm the esterification process. ${ }^{30}$

Glass transition temperature $(\mathrm{Tg})$ can be defined as the change in the relaxation behavior of polymer chains. Below the $\mathrm{Tg}$, polymer chains are virtually frozen and act like a rigid spring (glassy state). However, above $\mathrm{Tg}$, polymer chains achieve enough thermal energy to move more freely (rubbery state) like a weak spring. ${ }^{31}$ CMCAB is an amphiphilic polymer with a high glass transition temperature $\left(\mathrm{Tg} 137^{\circ} \mathrm{C}\right)$, which indicates high efficiency in drug-polymer interaction. $^{32}$

For $\mathrm{CMCAB}$, the $\mathrm{Tg}$ value was found to be $138.35{ }^{\circ} \mathrm{C}$. The single $\mathrm{Tg}$ indicated attractive molecular interactions and a high degree of compatibility of all the materials. ${ }^{21}$ The DSC curves showed that $\mathrm{CMCAB}$ is a glassy thermoplastic cellulose derivative, with a glass transition temperature $(\mathrm{Tg})$ of $138.35{ }^{\circ} \mathrm{C}^{33}$ It is evident that the thermal properties of $\mathrm{CMC}$ greatly improved by esterification. ${ }^{34}$

\section{CONCLUSION}

The thermal decomposition process of cellulose, CMC and CMCA could be divided into two major reaction steps, where the first weight loss of cellulose, CMC and CMCA was of 4.86 , 6.49 and $7.93 \%$ at $60.7,49.2$ and $51.3{ }^{\circ} \mathrm{C}$, respectively. This initial weight loss was followed by the main decomposition step at 353, 295 and $329{ }^{\circ} \mathrm{C}$ (accounting for a weight loss of 75.5, 59.3 and $92.0 \%$ ) for cellulose, CMC and CMCA, respectively. The thermal decomposition process of $\mathrm{CMCAB}$ could be divided into three major reaction steps. The initial weight loss at $46.2{ }^{\circ} \mathrm{C}$ (average weight loss of $2.76 \%$ ) was likely caused by adsorbed moisture. The next major weight 
loss, at $278{ }^{\circ} \mathrm{C}$ (mass loss of 33\%) consisted of several simultaneous processes, such as depolymerization, dehydration and decomposition. The third decomposition step represented the maximum degradation rate event at $357{ }^{\circ} \mathrm{C}$ (average weight loss of $59.4 \%$ ), which was attributed to the decomposition of the carbonaceous residues. However, the main weight loss shifted to higher temperature, which may confirm the increased thermal stability of $\mathrm{CMCAB}$, compared to those of cellulose, CMC and CMCA. The activation energy of CMCAB was the highest due to the dissolution of the amorphous parts of CMC during the modifications.

The DSC curve of cellulose showed two endothermic peaks, at 72.1 and $358{ }^{\circ} \mathrm{C}$, attributed to the removal of moisture and the decomposition of cellulose, respectively. In the case of CMCAB, there were three endothermic bands at $60.6{ }^{\circ} \mathrm{C}$, attributed to the loss of bound water and two bands at 200 and $359{ }^{\circ} \mathrm{C}$, reflecting the decomposition process of the synthesized copolymer. These changes in the pattern of thermal transitions in the $\mathrm{CMCAB}$ copolymer, when compared to cellulose, confirmed the esterification process.

The DSC curves recorded for pure CMCAB showed that CMCAB was a glassy thermoplastic cellulose derivative, with glass transition temperature at $138.35{ }^{\circ} \mathrm{C}$.

ACKNOWLEDGEMENT: The authors would like to express their gratitude to the National Research Centre, Egypt, for the financial support of the current work through project number 10130101 .

\section{REFERENCES}

1 A. Salama, R. E. Abou-Zeid, M. El-Sakhawy and A. El-Gendy, Int. J. Biol. Macromol., 74, 155 (2015), https://doi.org/10.1016/j.ijbiomac.2014.11.041

2 S. Kamel, N. Ali, K. Jahangir, S. M. Shah and A. A. El-Gendy, eXPRESS Polym. Lett., 2, 758 (2008), https://doi.org/10.3144/expresspolymlett.2008.90

3 V. B. Vedula, M. Chopra, E. Joseph and S. Mazumder, Appl. Nanosci., 6, 197 (2016), https://doi.org/10.1007/s13204-015-0421-y

4 X. Dong, S. Hou, H. Mao, J. Zheng and S. Zhang, J. Membrane Sci., 518, $31 \quad$ (2016), https://doi.org/10.1016/j.memsci.2016.06.036

5 M. El-Sakhawy, S. Kamel, A. Salama and H.-A. Sarhan, J. Drug Deliv., 2014, 575969 (2014), https://doi.org/10.1155/2014/575969
6 K. J. Edgar, C. M. Buchanan, J. S. Debenham, P. A. Rundquist, B. D. Seiler et al., Prog. Polym. Sci., 26, 1605 (2001), https://doi.org/10.1016/S00796700(01)00027-2

7 M. E. McHenry, M. A. Willard and D. E. Laughlin, Prog. Mater. Sci., 44, 291 (1999), https://doi.org/10.1016/S0079-6425(99)00002-X

8 R. Bodirlău, C.-A. Teacă, A.-M. Resmeriță and I. Spiridon, Cellulose Chem. Technol., 46, 381 (2012), http://www.cellulosechemtechnol.ro/pdf/CCT56(2012)/p.381-387.pdf

9 S. Yaman, Energ. Convers. Manage., 45, 651 (2004), https://doi.org/10.1016/S0196-8904(03)001778

10 G. S. Said, F. H. Abd-El Kader, M. M. El Naggar and B. A. Anees, Carbohyd. Polym., 65, 263 (2006), https://doi.org/10.1016/j.carbpol.2006.01.012

11 S. Kamel, H. Abou-Yousef, M. Yousef and M. ElSakhawy, Carbohyd. Polym., 88, 250 (2012), https://doi.org/10.1016/j.carbpol.2011.11.090

12 A. M. Adel, Z. H. Abd El-Wahab, A. A. Ibrahim and M. T. Al-Shemy, Bioresour. Technol., 101, 4446 (2010), https://doi.org/10.1016/j.biortech.2010.01.047

13 A. Salama, M. Neumann, C. Günter and A. Taubert, Beilstein J. Nanotechnol., 5, 1553 (2014), https://doi.org/10.3762/bjnano.5.167

14 A. M. Adel, H. Abou-Youssef, A. A. El-Gendy and A. M. Nada, Nature Sci., 8, 244 (2010), https://doi.org/10.7537/marsnsj080810.29

15 L. Golbaghi, M. Khamforoush and T. Hatami, Carbohyd. Polym., 174, $780 \quad$ (2017), https://dx.doi.org/10.1016/j.carbpol.2017.06.123

16 D. Klemm, B. Philipp, T. Heinze, U. Heinze and W. Wagenknecht (Eds.), "Comprehensive Cellulose Chemistry", Vol. 1: Fundamentals and Analytical Methods, Wiley-VCH, Chichester, 1998, https://doi.org/10.1021/ja9857514

17 P. K. Chatterjee and C. M. Conrad, J. Polym. Sci. Pol. Chem., 6, $3217 \quad$ (1968), https://doi.org/10.1002/pol.1968.150061202

18 A. Salama, M. El-Sakhawy and S. Kamel, Int. J. Biol. Macromol., 93, $1647 \quad$ (2016), https://doi.org/10.1016/j.ijbiomac.2016.04.029

19 A. M. A. Nada and M. L. Hassan, J. Appl. Polym. Sci., $\quad \mathbf{1 0 2}, \quad 1399 \quad$ (2006), https://doi.org/10.1002/app.24255

20 M. A. Henrique, W. P. F. Neto, H. A. Silvério, D. F. Martins, L. V. A. Gurgel et al., Ind. Crop. Prod., 76, 128

https://doi.org/10.1016/j.indcrop.2015.06.048

(2015)

21 P. Sathiyanarayanan, R. J. Karunakaran, T. Gomathiand and P. N. Sudha, Int. J. Novel Trends

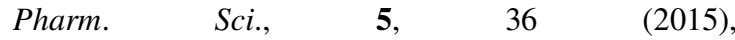
www.ijntps.com/sites/default/files/0084.pdf

22 A. A. Hanna, A. H. Basta, H. El-Saied and I. F. Abadir, Polym. Degrad. Stabil., 63, 293 (1999), https://doi.org/10.1016/S0141-3910(98)00108-6

${ }_{23}$ M. El-Sakhawy, S. Kamel, A. Salama and H.-A. Sarhan, Cellulose Chem. Technol., 52, 193 (2018), 
http://www.cellulosechemtechnol.ro/pdf/CCT34(2018)/p.193-200.pdf

24 B. Tosh, Indian J. Chem. Techn., 18, 451 (2011), http://nopr.niscair.res.in/handle/123456789/13277

25 L. Dai, L.-Y. Wang, T.-Q. Yuan and J. He, Polym. Degrad. Stabil., 99, $233 \quad$ (2014), https://doi.org/10.1016/j.polymdegradstab.2013.10.024

26 A. Singh and G. V. Mooter, Adv. Drug Deliver. $\operatorname{Rev.,}$ 100, 27 (2016), https://doi.org/10.1016/j.addr.2015.12.010

27 I. M. El-Sherbiny, A. Salama and A. A. Sarhan, Int. J. Polym. Mater., 58, $453 \quad$ (2009), https://doi.org/10.1080/00914030902936519

28 P. Antoniammal and D. Arivuoli, J. Nanomater., 2012, 415797

(2012), https://doi.org/10.1155/2012/415797

${ }^{29}$ O. A. Yeshchenko, I. M. Dmytruk, A. A. Alexeenko and A. M. Dmytruk, Phys. Rev. B, 75, 085434 (2007),

https://doi.org/10.1103/PhysRevB.75.085434

30 P. H. F. Pereira, H. C. J. Voorwald, M. O. H. Cioffi, D. R. Mullinari, S. M. Da Luz et al., BioResources, 6, $2471 \quad$ (2011), https://bioresources.cnr.ncsu.edu/BioRes_06/BioRes_0 6_3_2471_FernandesP_VCMDP_SCB_Pulp_Bleach_ Therm_Chem_Char_987.pdf
31 M. C. Shen and A. Eisenberg, Prog. Solid State Ch., 3, 407 (1967), https://doi.org/10.1016/00796786(67)90039-8

32 B. Li, H. Liu, M. Amin, L. A. Wegiel, L. S. Taylor et al., Cellulose, 20, $2137 \quad$ (2013), https://doi.org/10.1007/s10570-013-9970-y

33 J. A. Júnior, Y. Kawano and D. F. S. Petri, Mater.

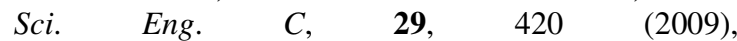
https://doi.org/10.1016/j.msec.2008.08.018

34 K. Huang, M. Zhang, G. Zhang, X. Jiang and D. Huang, Cellulose Chem. Technol., 48,199 (2014), http://www.cellulosechemtechnol.ro/pdf/CCT34(2014)/p.199-207.pdf 